\title{
Penerapan Metode Six Sigma di PT Triangle Motorindo
}

\author{
Arfan Bakhtiar ${ }^{1}$, Bintang Rachvadani Dzakwan ${ }^{1}$, Murni Elfrida Br Sipayung ${ }^{1}$, Claudha Alba Pradhana ${ }^{1}$ \\ ${ }^{1}$ Departemen Teknik Industri, \\ Fakultas Teknik, Universitas Diponegoro, Jalan Prof. Soedarto, SH, Kampus Undip Tembalang, Semarang, \\ Indonesia 50275 \\ email : arfanbakhtiar@lecturer.undip.ac.id \\ doi: https://doi.org/10.31315/opsi.v13i2.4066
}

Received: 10 ${ }^{\text {th }}$ December 2020; Revised: $19^{\text {th }}$ December 2020; Accepted: $23^{\text {rd }}$ December 2020; Available online: 23 ${ }^{\text {rd }}$ December 2020; Published regularly: December 2020

\begin{abstract}
PT. Triangle Motorindo is the sole agent holder of the VIAR Brand as one of the largest manufacturers of threewheeled motorcycles in Indonesia. This company was founded in 2000 and has grown as one of the largest manufacturers of three-wheeled motorcycles in Indonesia. As one of the largest producers of three-wheeled motorbikes in Indonesia, PT Triangle Motorindo must be able to maintain and continue to improve the quality of their products in order to remain strong in the competition. In the production process, this company needs to reduce the number of defects that often occur in the production process, so that it decides to use the Six Sigma method to overcome these problems. Six Sigma is a statistical concept that measures a process related to defects or damage. Reaching six sigma means that a process generates only 3.4 defects per million chance, in other words, that it is running almost perfectly. The company is in a position where the defect type reaches 3.55 sigma. Therefore, the DMAIC method is used to increase it to 4 sigma. After the improvement stage is carried out, the company is expected to be able to reach the 4 sigma stage
\end{abstract}

Keywords: Six Sigma; DMAIC; PT. Triangle Motorindo; Improvement

\begin{abstract}
ABSTRAK
PT. Triangle Motorindo adalah agen tunggal pemegang Merek VIAR sebagai salah satu produsen terbesar sepeda motor roda tiga di Indonesia. Perusahaan ini berdiri sejak tahun 2000 dan telah berkembang sebagai salah satu produsen terbsesar sepeda motor roda tiga di Indonesia. Sebagai salah satu produsen terbesar sepeda motor roda tiga di Indonesia, tentu PT Triangle Motorindo harus mampu menjaga dan terus meningkatkan kualitas produk mereka agar bisa tetap kokoh dalam bersaing. Di dalam proses produksinya, perusahaan ini perlu untuk mengurangi jumlah defect yang sering terjadi dalam proses produksi, sehingga memtuskan untuk menggunakan metode Six Sigma untuk mengatasi permasalahan tersebut. Six Sigma merupakan konsep statistik yang mengukur suatu proses yang berkaitan dengan cacat atau kerusakan. Mencapai enam sigma berarti bahwa suatu proses menghasilkan hanya 3,4 cacat per sejuta peluang, dengan kata lain bahwa proses itu berjalan hampir sempurna. Perusahaan berada pada posisi dimana jenis cacat yang ada mencapai 3,55 sigma. Maka dari itu, digunakan metode DMAIC untuk menaikkannya menjadi 4 sigma. Setelah dilakukan tahap improvement, perusahaan diharapkan mampu mencapai tahap 4 sigma.
\end{abstract}

Kata Kunci: Six Sigma; DMAIC; PT. Triangle Motorindo; Improvement

\section{PENDAHULUAN}

Indonesia merupakan negara berkembang yang pertumbuhan industrinya sedang meningkat dan semakin kompleks seiring dengan adanya kemajuan teknologi. Perusahaan - perusahaan yang ada baik dalam bidang manufaktur maupun jasa, berlomba lomba bersaing untuk memenangkan pasar baik secara nasional maupun internasional guna tetap bertahan dan mendukung pertumbuhan negara. Adanya persaingan antar perusahaan yang cukup ketat dan meningkatnya kompleksitas dari kebutuhan dan permintaan pelanggan mendorong keseluruhan industri dan organisasi untuk meningkatkan kualitas dari produk dan layanan yang diberikan lebih baik lagi agar dapat unggul secara kompetitif strategis (Jirasukprasert et al, 2014). Salah satu indikator penting agar suatu perusahaan dapat bertahan dalam persaingan adalah kepuasan pelanggan. 
Kepuasan pelanggan merupakan suatu tingkatan dimana kebutuhan, keinginan dan harapan dari pelanggan dapat terpenuhi yang akan mengakibatkan terjadinya pembelian ulang atau kesetiaan yang berlanjut. Kotler (1997) mendefinisikan bahwa Kepuasan pelanggan adalah pengalaman perasaan dari seseorang mengenai perbandingan kinerja/hasil yang telah dipersepsikan dibandingkan dengan ekspektasinya. Kepuasan pelanggan sendiri akan tercapai jika harapan - harapan mereka dapat dipenuhi dengan baik. Agar dapat menjadi kompetitif poin utamanya adalah pada kemampuan untuk dapat melampaui/melebihi kebutuhan dan ekpekstasi dari pelanggan itu sendiri, lalu menyediakan sesuai dengan permintaan pelanggan, menyajikan produk yang memikili kualitas tinggi tetapi berbiaya rendah, tepat waktu, dan setiap waktu (Madanhire \& Mbohwa, 2016). Oleh karena itu, pihak perusahaan harus menjaga kualitas dari produk yang dihasilkan. Perusahaan perlu melakukan upaya pengendalian kualitas yang dilakukan secara berkala agar kualitas produk yang dihasilkan tetap sesuai dengan spesifikasi dari pelanggan. Langkah yang dapat dilakukan untuk pengendalian kualitas salah satunya dapat diwujudkan dengan cara meminimasi cacat yang timbul pada produk.

PT Triangle Motorindo merupakan agen tunggal pemegang merk VIAR berdiri dengan tekat untuk menjadi produsen terbesar sepeda motor roda tiga di Indonesia. Salah satu bukti yang diberikan adalah komitmen PT. Triangle Motorindo dalam memproduksi sepeda motor VIAR berkualitas tinggi dan dengan harga yang terjangkau kepada masyarakat Indonesia agar VIAR dapat menjadi leading brand otomotif di Indonesia. Sebagai salah satu produsen terbesar sepeda motor roda tiga di Indonesia, tentu PT Triangle Motorindo harus mampu menjaga dan terus meningkatkan kualitas produk mereka agar bisa tetap kokoh dalam bersaing. Selain itu, perusahaan juga akan mendapat penilaian serta image yang baik jika sistem yang diterapkan ramah terhadap pekerja tetapi tetap efisien dan efektif.

New Karya 150 \& 200 R/L merupakan produk motor roda tiga andalan dari VIAR. Walaupun menjadi produk andalannya, di dalam proses produksinya, masih terdapat banyak kendala yang ditemukan seperti masih banyak ditemukan cacat/defect pada produk setelah selesai dirakit pada lini produksi. Ketika terjadinya cacat, perusahaan harus mengeluarkan ekstra waktu dan uang hanya untuk melakukan rework dari produk cacat/defect tersebut sebelum dipasarkan. Maka dari itu dibutuhkan pengendalian kualitas untuk mencegah terjadinya cacat pada produk produk tersebut.

Metodologi six sigma DMAIC, memiliki kegunaan untuk memperbaiki suatu proses yang sudah ada sebelumnya dan terkbukti telah berhasil dalam mengurangi biaya, meningkatkan waktu siklus, menghilangkan cacat pada produk, dan meningkatkan kepuasan pelanggan secara signifikan dengan meningkatkan profitabilitas di banyak industri dan organisasi di seluruh dunia. Tujuan utama dari six sigma adalah pencapaian level yang sempurna dengan mewujudkan 3,4 error rate di dalam satu juta produksi (Erdoğan \& Canatan, 2015). Six Sigma merupakan suatu metode perbaikan kualitas dengan basis statistik yang dilakukan secara komprehensif menggunakan metode DMAIC (Define, Measure, Analyse, Improve, Control). Varsha Karandikar (2014) secara efektif menerapkan pendekatan DMAIC dalam penelitiannya untuk mengatasi masalah di industri manufaktur filter seperti variasi proses, penolakan, dan pengerjaan ulang produk. Akar penyebab utama masalah diidentifikasi melalui diagram sebab dan akibat, FMEA, dll. Six sigma terdiri dari lima tahapan yang dimulai dari define atau sebagai fase penentuan masalah, lalu measure merupakan fase pengukuran tingkat kecacatan yang terjadi, dilanjutkan analyze sebagai fase analisa penyebab - penyebab kemungkinan terjadinya permasalahan di dalam proses, setelah itu improve sebagai fase peningkatan proses dan penghilangan penyebab terjadinya cacat, dan diakhiriri dengan control sebagai fase pengawasan kinerja proses agar cacat tidak timbul kembali (Pande \& Holpp, 2002). Penerapan six sigma sendiri sebagai suatu filosofis manajemen perlu partisipasi dari seluruh anggota dari perusahaan sebagai suatu budaya dan sesuai dengan visi misi dari perusahaan. Hal ini bertujuan guna meningkatkan efisiensi dari proses bisnis yang ada dan meraih kepuasan pelanggan, sehingga perusahaan akan mendapatkan penilaian serta image yang baik di khalayak umum (Harry \& Schroeder, 2005). Six sigma bekerja dengan cara menekankan penghilangan kesalahan, penghilangan waste, dan mengecilkan rework 
dari produk yang cacat sehingga biaya yang awalnya ditujukan untuk penanganan hal - hal tersebut dapat diminimalisir dan imbasnya perusahaan/organisasai akan medapatkan keuntungan yang meningkat (Pande, 2002).

\section{METODE}

Sebagai salah satu perusahaan produsen terbesar sepedar motor roda tiga di Indonesia, PT. Triangle Motorindo harus dapat memproduksi produknya dengan kualitas yang tinggi agar tetap kokoh dalam persaingan produk sejenis. Ketidaksesusaian produk hasil proses produksi sendiri oleh perusahaan dibagi menjadi 2 macam jenis, yaitu cacat proses dan cacat material. Cacat proses terjadi saat pada proses perakitan produk lalu terdapat kesalahan

pengerjaanya baik yang disebabkan karena operator perakitan, mesinnya, maupun faktor lainnya. Sedangkan cacat material adalah ketika material - material penyusun produk dirakit lalu terdapat kecacatan pada material tersebut yang bukan disebabkan oleh operator perakitan, mesin perakitan, atau lainnya tetapi karena memang materialnya cacat. Jika terdapat produk dengan salah satu cacat tersebut, produk harus direject dan dilakukan rework.

Pada laporan ini penulis berfokus pada ketidaksesuaian yang terjadi pada produk New Karya 150 \& $200 \mathrm{R} / \mathrm{L}$ yang tidak memenuhi syarat/ cacat. Produk yang tidak memenuhi syarat tersebut akan di-reject dan diproses ulang/ rework untuk memperbaiki kecacatannya sehingga memenuhi syarat mutu dari perusahaan. Pengerjaan ulang tersebut akan menambah lamanya waktu produksi dan juga akan memberikan biaya tambahan bagi perusahaan untuk pengerjaannya. Untuk meminimalisir terjadinya ketidaksesuaiian produk tersebut maka perlu dilakukan pengendalian kualitas oleh perusahaan. Metode yang digunakan pada penelitian itu dalam pengendalian kualitas berlandaskan pada prinsip metode Six Sigma sehingga perusahaan dapat mengetahui faktor - faktor apa saja yang perlu diperbaiki terlebih dahulu. Pada jurnal ini penelitian hanya dilakukan sampai pada tahap define, measure, analyze, dan improve. Tahap control masih belum dapat dilaksanakan hal tersebut diakibatkan karena pada tahap control sudah mulai memasuki tahapan implementasi yang didapatkan dari tahapan - tahapan sebelumnya. Selain itu tahapan control masih belum dapat dilaksanakan karena adanya keterbatasan waktu penelitian dan juga peneliti tidak dapat berpartisipasi langsung atas pengambilan keputusan terkait aktifitas aktifitas dalam proses produksi di perusahaan.

\subsection{Pengumpulan Data}

Data yang digunakan dalam laporan ini adalah data laporan bulanan di departemen Produksi dari bulan Oktober 2018 - Desember 2019. Data ini dikumpulkan oleh pihak quality control pada departemen Produksi. Pada table 1 diperlihatkan data total banyaknya cacat bulanan pada departemen Produksi (study kasus produk New Karya 150 \& 200 R/L):

Tabel 1. Data Jumlah Cacat pada Departement Produksi

\begin{tabular}{cccc}
\hline NO & Bulan & $\begin{array}{c}\text { Unit } \\
\text { Diproduksi }\end{array}$ & $\begin{array}{c}\text { Unit } \\
\text { Cacat }\end{array}$ \\
\hline 1 & Okt-18 & 1486 & 60 \\
2 & Nov-18 & 1388 & 55 \\
3 & Des-18 & 1141 & 69 \\
4 & Jan-19 & 1250 & 42 \\
5 & Feb-19 & 1225 & 38 \\
6 & Mar-19 & 1276 & 55 \\
7 & Apr-19 & 972 & 29 \\
8 & Mei-19 & 1290 & 30 \\
9 & Jun-19 & 578 & 21 \\
10 & Jul-19 & 1417 & 39 \\
11 & Agu-19 & 1570 & 41 \\
12 & Sep-19 & 1113 & 52 \\
13 & Okt-19 & 1257 & 65 \\
14 & Nov-19 & 1447 & 74 \\
15 & Des-19 & 1432 & 83 \\
\hline
\end{tabular}

\section{HASIL DAN PEMBAHASAN}

Data yang digunakan telah dilakukan pengujian dengan uji keseragaman data, uji kecukupakan data dan uji kenormalan data. Untuk hasil uji keseragaman data adalah data yang digunakan seragam karena tidak ada data yang melewati batas atas maupun batas bawah.

Uji kecukupan data yang telah dilakukan menunjukkan bahwa data yang digunakan adalah cukup karena $\mathrm{N}>\mathrm{N}^{\prime}(15>14)$, maka data yang digunakan mencukupi syarat untuk pengolahan data lebih lanjut. Sedangkan untuk uji kenormalan data juga menunjukkan bahwa data yang jumlah cacat yang digunakan berdistribusi normal karena nilai KSnya berada diluar daerah kritis yang bernilai $>0,235$. Disamping data berada diluar daerah kritis $(0,143<0,235)$, data juga berada didaerah garis 
tengah yang menandakan nilainya tersebar disekitar nilai

\subsection{Tahap DMAIC}

\section{A. Define}

Pada tahap define akan dijelaskan dan diidentifikasi permasalahan yang terjadi pada metode Six Sigma. Produk yang akan diteliti yaitu New Karya 150 \& 200 R/L. Untuk mengidentifikasi proses - proses kunci pada perusahaan digunakan SIPOC (Suppliers Input - Process - Output - Customer). SIPOC sendiri merupakan tool yang sederhana dan mudah dalam penggunaanya serta berguna dalam proses identifikasi pemasok, masukan, arus proses tingkat tinggi, keluaran, dan pelanggan (Peruchi et al, 2020). Pada gambar 3 ditunjukkan SIPOC dari PT. Triangle Motorindo

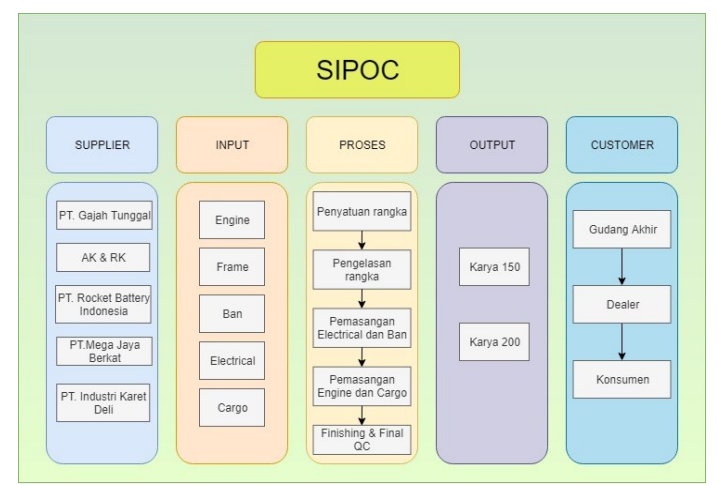

Gambar 3. SIPOC PT. Triangle Motorindo

Pada tabel 1.2 ditunjukkan presentase masing- masing jenis reject pada produk New Karya $150 \quad \& \quad 200 \quad \mathrm{R} / \mathrm{L}$ yang diolah menggunakan diagram Paretto:

Tabel 2. Jumlah kumulatif Reject Produk New Karya $150 \& 200 \mathrm{R} / \mathrm{L}$

\begin{tabular}{ccc}
\hline NO & Jenis Cacat & $\begin{array}{c}\text { Jumlah } \\
\text { Cacat }\end{array}$ \\
\hline 1 & Frame Miring & 277 \\
2 & Cargo Bottom Penyok & 24 \\
3 & Lamp Jauh Dekat Terbalik & 18 \\
4 & Lampu Fr Winker L Mati & 36 \\
5 & Lampu Fr Winker R Mati & 22 \\
6 & Cover Steering Handle Miring & 13 \\
7 & Lamp kota Fr mati Vitting tidak & 78 \\
8 & Lamp Kota Fr Mati Bulb Mati & 37 \\
9 & Front Wheel Miring & 81 \\
10 & Cargo Bottom Tidak Pas (Tidak & 14 \\
11 & Center) & 13 \\
12 & Fr Fender Miring & 11 \\
13 & Tube Radiator Tertekuk & 8
\end{tabular}

\begin{tabular}{ccc}
14 & Steering Stem Kekencangan & 7 \\
15 & Rr Fender Tidak Pas/ Miring & 37 \\
16 & Bolt Cargo Side L Tidak Ada 1 & 24 \\
17 & Muffler Bocor & 17 \\
18 & Bolt Cargo Side R kendor & 16 \\
19 & Lamp Reverse Terbalik Dengan & 13 \\
20 & Lamp Winker R Rr & 7 \\
\hline & Pedal Persneling Tidak Pas & 753 \\
\hline
\end{tabular}

Berdasarkan hasil pengumpulan data dan wawancara terhadap pihak terkait, didapat 2 kategori jenis cacat yang memungkinkan dan dianggap potensial timbulnya defect pada departemen finisihing:

Tabel 3. Identifikasi Critical to Quality

\begin{tabular}{|c|c|c|}
\hline No. & $\begin{array}{c}\text { Kategori } \\
\text { Cacat }\end{array}$ & Definisi Operasional \\
\hline 1 & $\begin{array}{l}\text { Cacat } \\
\text { produk tidak } \\
\text { sesuai } \\
\text { dengan } \\
\text { desain }\end{array}$ & $\begin{array}{l}\text { Produk memiliki bentuk yang } \\
\text { berbeda dari standart desain } \\
\text { yang telah ditentukan oleh } \\
\text { perusahaan hal tersebut baik } \\
\text { disebabkan karena proses } \\
\text { perakitannya sendiri maupun } \\
\text { karena kesalahan dari faktor } \\
\text { lainnya. }\end{array}$ \\
\hline 2 & $\begin{array}{l}\text { Cacat } \\
\text { produk tidak } \\
\text { berfungsi } \\
\text { sebagaimana } \\
\text { mestinya }\end{array}$ & $\begin{array}{l}\text { Produk tidak berfungsi } \\
\text { sebagaimana mestinya adalah } \\
\text { ketika produk yang telah } \\
\text { dirangkai pada proses } \\
\text { produksi mengalami } \\
\text { kecacatan yang berupa fungsi } \\
\text { dari produk tersebut tidak } \\
\text { berfungsi secara gunanya baik } \\
\text { penyebabnya adalah karena } \\
\text { kesalahan pada proses } \\
\text { produksinya sendiri maupun } \\
\text { karena faktor-faktor lainnya. }\end{array}$ \\
\hline
\end{tabular}

Berdasarkan 6 peringkat teratas dari persentase reject produk pada diagram pareto diatas, untuk jenis cacat frame miring, front wheel miring, lamp kota Fr mati vitting tidak pas, dan Rr Fender tidak pas/miring masuk ke dalam kategori cacat produk tidak sesuai dengan desain. Sedangkan untuk jenis cacat yang masuk ke kategori cacat produk tidak berfungsi sebagaimana mestinya adalah Lamp kota Fr mati bulb mati dan lampu Fr winker L mati. 


\section{B. Measure}

\section{- Peta kendali P}

Berdasarkan gambar 4, tidak terdapat data yang diluar batas terkendali. Hal ini menunjukkan bahwa jumlah cacat pada departemen produksi terkontrol secara statistik. Berikut merupakan grafik peta kendali $p$ iterasi 0 :

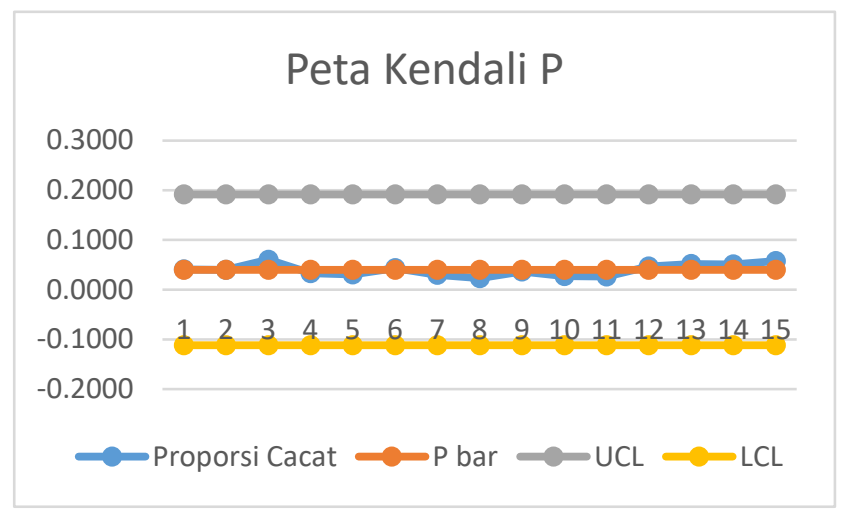

Gambar 4. Grafik Peta Kendali P

\section{- Pengukuran Tingkat DPMO dan Level Sigma}

Sebelum melakukan peningkatan kualitas sigma, maka harus dilakukan perbandingan antara nilai DPMO periode dengan DPMO proses serta nilai sigma proses dengan sigma periode.

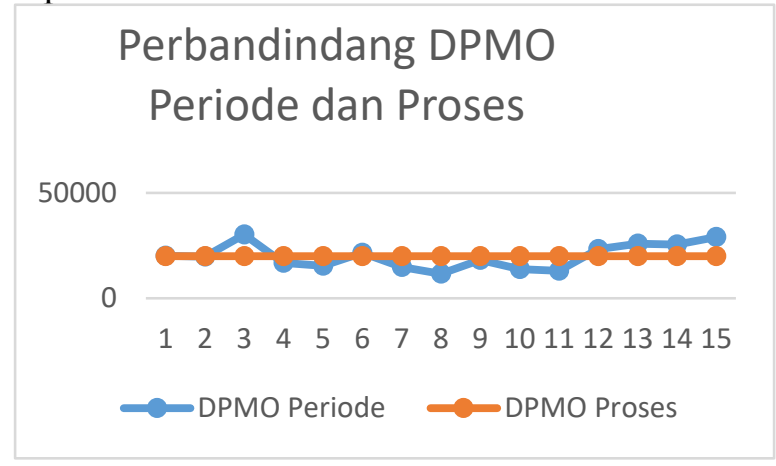

Gambar 5. Perbandingan Nilai DPMO

\section{Perbandingan Six Sigma Periode dan Proses}

4

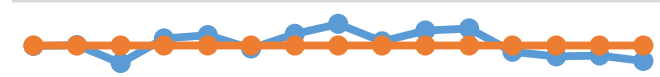

$\begin{array}{lllllllllllllll}1 & 2 & 3 & 4 & 5 & 6 & 7 & 8 & 9 & 10 & 11 & 12 & 13 & 14 & 15\end{array}$

-Six Sigma Periode $\quad$ Six Sigma Proses

Gambar 6. Perbandingan Nilai Six Sigma

Level sigma dari perhitungan diperoleh nilai DPMO proses sebesar 19981,96 dan level sigma proses sebesar 3,554121. Nilai level sigma tersebut sudah bagus karena rata-rata nilai sigma untuk perusahaan Indonesia adalah 2-3 sigma.

\section{- Menghitung Peningkatan Sigma dan Penentuan Target DPMO}

Diasumsikan, setiap periodenya perusahaan harus dapat meningkatkan nilai sigma mencapai nilai $4 \sigma$. Perhitungan target kinerja departemen produksi adalah sebagai berikut:

$$
\begin{aligned}
& \text { - Menghitung peningkatan sigma } \\
& \text { Peningkatan sigma }(\%)= \\
& \frac{\text { sigma target-sigma baseline }}{\text { sigma baseline }} \times 100 \%=12,549 \%
\end{aligned}
$$

DPMO untuk nilai $4 \sigma$ adalah 6210 , maka:

$$
\begin{aligned}
& \text { Penurunan DPMO }(\%)= \\
& \frac{\text { DPMO baseline }- \text { DPMO Targer }}{\text { DPMO baseline }} \times 100 \%=68,922 \%
\end{aligned}
$$

Nilai sigma yang ingin dicapai adalah 4 sigma, sehingga perusahaan perlu melakukan peningkatan sebesar $12,549 \%$ dengan besar penurunan DPMO sebesar 68,922\%.

\section{Analyze}

Tujuan dari tahap ini ialah mengidentifikasi penyebab masalah yang paling berdampak besar pada CTQ menggunakan diagram fishbone.

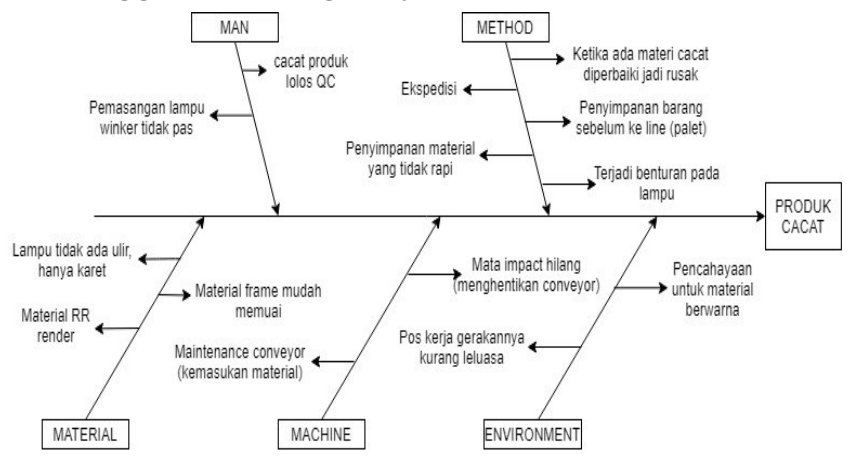

Gambar 7. Diagram Fishbone untuk Penyebab Kecacatan Produk New Karya 150 \& 200 R/L

\section{Improve}

Pada tahapan improve, solusi - solusi dari permasalahan yang telah ditunjukkan pada tiga tahapan sebelumnya (define, measure, dan analyze) akan ditentukan. Langkah awal penentuan solusi ini dimulai dengan brainstorming dengan pihak - pihak terkait untuk menentukan solusi dari masalah kegagalan uji fungsional. Lalu dilanjutkan dengan pengujian dari solusi yang telah 
diajukan sebelumnya apakah solusi - solusi tersebut masih memenuhi persyaratan yang telah ditentukan, dan setelah itu hasil dari solusi - solusi yang akan digunakan dilakukan penilaian (Pimsakul et al,2013). Setelah mengetahui sumber-sumber dari akar penyebab masalah kualitas yang secara sistematis telah digambarkan pada fishbone diagram, maka langkah selanjutnya yang harus dilakukan pada tahap improve adalah menetapkan rencana tindakan (action plan) untuk meningkatkan nilai sigma pada departemen produksi sehingga rework dapat diminimalisir. Tahap improve dilakukan pada kelima penyebab utama yaitu man, method, material, machine, dan environment. Dari kelima faktor diatas yang telah disebutkan pada fishbone diagaram, maka dapat diberikan usulan mengenai faktor-faktor diatas:

Tabel 4. Usulan Perbaikan

\begin{tabular}{|c|c|c|}
\hline Faktor & Masalah & Improve \\
\hline \multirow{2}{*}{ Man } & $\begin{array}{l}\text { Pemasangan lampu } \\
\text { winker tidak pas }\end{array}$ & \multirow{2}{*}{$\begin{array}{l}\text { Memberikan training bagi para operator mengenai perakitan } \\
\text { produk yang sesuai dan memberikan pemahaman secara } \\
\text { mendalam mengenai proses yang ada sehingga dapat mencegah } \\
\text { terjadinya defect. }\end{array}$} \\
\hline & Cacat produk lolos QC & \\
\hline \multirow{5}{*}{ Method } & $\begin{array}{l}\text { Ketika ada material yang } \\
\text { cacat lalu diperbaiki } \\
\text { justru menyebabkan } \\
\text { material tetrsebut } \\
\text { menjadi rusak. }\end{array}$ & $\begin{array}{l}\text { Perlu dilakukan pengujian apakah yang salah memang pada } \\
\text { metode perbaikannya atau memang pada materialnya sehingga } \\
\text { dapat dilakukan upaya pencegahan terhadap terjadinya kerusakan } \\
\text { material pada material yang akan diperbaiki. }\end{array}$ \\
\hline & Ekspedisi & \multirow{4}{*}{$\begin{array}{l}\text { Perlunya pencarian ekspedisi yang lebih terjamin pengirimannya/ } \\
\text { melakukan pengiriman secara mandiri. } \\
\text { Perlunya dilakukan pemahaman baik ke seluruh pihak perusahaan } \\
\text { bahwa pentingnya pengendalian kualitas dimulai dari hal yang } \\
\text { paling kecil seperti contohnya pada penyimpanan material - } \\
\text { material yang akan dirakit. Dengan layout gudang penyimpanan } \\
\text { yang baik nantinya akan mencegah terjadinya defect material } \\
\text { yang akan dirakit dan akan memberi nilai lebih bagi perusahaan. }\end{array}$} \\
\hline & $\begin{array}{c}\text { Penyimpanan barang } \\
\text { sebelum ke line (palet) }\end{array}$ & \\
\hline & $\begin{array}{l}\text { Penyimpanan material } \\
\text { yang tidak rapi }\end{array}$ & \\
\hline & $\begin{array}{l}\text { Terjadi benturan pada } \\
\text { lampu }\end{array}$ & \\
\hline \multirow{3}{*}{ Material } & $\begin{array}{l}\text { Lampu tidak ada ulir } \\
\text { hanya karet }\end{array}$ & $\begin{array}{l}\text { Pemberian ulir pada lampu sehingga lampu tidak mudah putus } \\
\text { karena lepas kurang kencang }\end{array}$ \\
\hline & $\begin{array}{l}\text { Material frame mudah } \\
\text { memuai }\end{array}$ & \multirow{2}{*}{$\begin{array}{l}\text { Perlunya penggantian/pemilihan material yang lebih baik lagi dan } \\
\text { juga mengadakan evaluasi supplier sebagai pertimbangan untuk } \\
\text { pemesanan material pada periode selanjutnya, }\end{array}$} \\
\hline & Material RR fender & \\
\hline \multirow[t]{2}{*}{ Machine } & Mata impact hilang & $\begin{array}{l}\text { Membuat rak khusus untuk menyimpan barang - barang kecil } \\
\text { seperti mata impact dan menyediakan mata impact dalam jumlah } \\
\text { lebih. Lalu memberikan beberapa lampu penerangan dibawah } \\
\text { conveyor untuk memudahkan mencari barang yang terjatuh di } \\
\text { bawah. Terakhir memberi peringatan dan pemahaman pada } \\
\text { operator pentingnya mengencangkan mata impact. }\end{array}$ \\
\hline & Maintenance conveyor & $\begin{array}{l}\text { Melakukan maintenance pada conveyor seminimal mungkin } \\
\text { seminggu sekali. }\end{array}$ \\
\hline \multirow{2}{*}{ Environment } & $\begin{array}{l}\text { Pencahayaan untuk } \\
\text { material berwarna }\end{array}$ & $\begin{array}{l}\text { Memberikan lampu khusus pada tiap pos kerja terutama pada } \\
\text { stasiun kerja yang berhubungan dengan pemasangan electrical / } \\
\text { kabel - kabel yang memiliki warna khusus di dalam } \\
\text { pemasangannya untuk mempermudah pekerjaan operator dalam } \\
\text { membedakan warna. }\end{array}$ \\
\hline & $\begin{array}{l}\text { Pos kerja gerakannya } \\
\text { kurang leluasa }\end{array}$ & $\begin{array}{l}\text { Meninjau ulang layout pos kerja pada tiap stasiun kerja dan } \\
\text { menanyakan langsung kepada para operator seberapa besar } \\
\text { ukuran yang dianggap mereka nyaman dalam aktifitasnya } \\
\text { melakukan pekerjaan }\end{array}$ \\
\hline
\end{tabular}




\section{E. Control.}

Pada tahap control, hal-hal yang dilakukan adalah mendefiniskan dan memvalidasi sistem kontrol dan monitoring, mengembangkan standar dan prosedur baru, mendokumentasikan proses baru atau proses yang telah dimodifikasi berdasarkan usulan perbaikan yang telah diberikan, dan melatih setiap pihak yang terlibat agar mampu menjalankan proses baru tersebut. Laporan ini belum menyertakan hasil tahap control dikarenakan keterbatasan waktu dan peneliti belum dapat terlibat secara langsung dalam proses pengambilan keputusan bersama para stakeholder yang terkait dengan proses kegiatan produksi, sehingga belum dapat diputuskan apakah solusi yang peneliti berikan dapat disetujui oleh pihak eksekutif.

\section{KESIMPULAN}

Dari penelitian yang telah dilakukan pada departemen Produksi PT. Triangle Motorindo mengenai produk New Karya $150 \& 200$ R/L didapat kesimpulan sebagai berikut: Jenis jenis cacat yang sering terjadi pada produksi New Karya 150 \& 200 R/L terdapat 20 jenis cacat yaitu Frame Miring, Cargo Bottom Penyok, Lamp Jauh Dekat Terbalik, Lampu Fr Winker L Mati, Lampu Fr Winker R Mati, dll .Berdasarkan perhitungan yang dilakukan, diketahui bahwa nilai DPMO pada baseline adalah sebesar 19981,96 sebagai kemungkinan terjadinya reject pada satu juta kali kesempatan produksi dan nilai sigma yang tercapai adalah $3,5541 \sigma$. Target nilai sigma yang dicari adalah $4 \sigma$ dengan nilai DPMO 6210, sehingga peningkatan nilai sigma yang harus dicapai adalah sebesar $12,549 \%$ dan penurunan nilai DPMO sebesar $68,922 \%$.

\section{DAFTAR PUSTAKA}

Erdoğan, A., \& Canatan, H. (2015). Literature Search Consisting of the Areas of Six Sigma's Usage. Procedia-Social and Behavioral Sciences, 195, 695-704.

Harry, M., \& Schroeder, R. (2005). Six Sigma: The breakthrough management strategy revolutionizing the world's top corporations. Crown Pub.

Jirasukprasert, P., Garza-Reyes, J. A., Kumar, V., \& Lim, M. K. (2014). A Six Sigma and DMAIC application for the reduction of defects in a rubber gloves manufacturing process. International Journal of Lean Six Sigma, 5(1), 2-21.

Karandikar, V., Sane, S., Sane, S., Jahagirdar, S., \& Shinde, S. (2014). Process Improvement in a Filter Manufacturing Industry through Six Sigma DMAIC Approach. International Journal of Current Engineering and Technology, 4(4), 2546-2556.

Kotler, P. (1997). Manajemen Pemasaran. New Jersey: A Simon \& Schuster Company.

Madanhire, I., \& Mbohwa, C. (2016). Application of statistical process control (SPC) in manufacturing industry in a developing country. Procedia Cirp, 40, 580-583.

Pande, P. (2002). The Six Sigma Way. Yogyakarta: Andi Yogyakarta.

Pande, P., \& Holpp, L. (2002). What is sigma?. New York: McGraw-Hill.

Peruchi, R. S., Junior, P. R., Brito, T. G., Paiva, A. P., Balestrassi, P. P., \& Araújo, L. M. M. (2020). Integrating Multivariate Statistical Analysis Into Six Sigma DMAIC Projects: A Case Study on AISI 52100 Hardened Steel Turning. IEEE Access, 8, 34246-34255.

Pimsakul, S., Somsuk, N., Junboon, W., \& Laosirihongthong, T. (2013). Production process improvement using the six sigma DMAIC methodology: a case study of a laser computer mouse production process. In The 19th International Conference on Industrial Engineering and Engineering Management (pp. 133146). Springer, Berlin, Heidelberg. 